World Mycotoxin Journal, 2011, 4 (4) 361-374

\title{
Biosensors and Nanomaterials and their Application for Mycotoxin
} Determination

\author{
Ibtisam E. Tothill
}

Cranfield Health, Cranfield University, Cranfield, Bedfordshire MK 43 0AL, England, UK.

Corresponding author: Tel: +44 07500 766487; i.tothill@cranfield.ac.uk 


\begin{abstract}
Analysis for mycotoxin in foods is a very important practice to ensure food quality and safety and to eliminate and control the risk of consuming contaminated foods. Hence, being able to analyse and detect mycotoxins in foods and drinks is a priority to comply with the legislative limits set by food authorities worldwide. Most analysis of these toxins is still conducted using conventional methods, however, biosensor methods are being developed to date as screening tools to be applied for field analysis. Biosensors, as tools have proofed to be able to provide rapid, sensitive, robust and cost effective quantitative methods for on-site testing. Developing biosensor devices for different mycotoxins are attracting much research interest in recent years with a range of devices are being developed and reported in the scientific literature. However, with the advent of nanotechnology and its impact on developing ultrasensitive devices, mycotoxins analysis is benefiting also from the advances taking place in applying nanomaterials in sensors development. This paper reviews the developments of biosensors and their applications for mycotoxins analysis and development of micro/nanoarray transducer and nanoparticles and their use in the development of new rapid devices.
\end{abstract}

Keyword: Mycotoxins, nanotechnology, nanomaterials, mico and nanoarrays, biosensors, molecular receptors, transducers. 


\section{Introduction}

Current concerns regarding food safety and quality requires a multidisciplinary approach based on a new generation of innovative and advanced technologies such as sensors/biosensors and tools to be used along the food chain for contaminants monitoring. Mycotoxins are one of the contaminants that require detection in foods and feeds to maintain good foods quality and to reduce their negative impact on human health. To control mycotoxins from contaminating food products there is a need for monitoring and control at different critical steps of the food chain to ensure food safety. These include monitoring of raw materials and food supply, monitoring during food processing, monitoring of final products and also during storage. To be able to carry these types of testing require a multidisciplinary know-how and the use of advanced technology to develop systems with clear innovative solutions to specific safety, quality and analytical requirements. The use of an integrated intelligence approach which will allow full interconnection and communication of multisensing systems is also advantages for food tractability. The use of nanotechnology inspired systems will be powerful in delivering and fulfilling these requirements.

To date there are emerging and innovative technologies being developed for mycotoxins analysis, and these can range from invasive, minimally invasive to non-invasive technologies. Biosensors and affinity sensor devices have been shown to have the ability to provide rapid, cost effective, specific and reliable quantitative and qualitative analysis (Tothill, 2001). The increase in the number of mycotoxins requiring monitoring and control and also the pressure to comply with legislations, considerable interest in developing multiarray sensors based on micro and nano systems as diagnostics and risk assessment tools have become an attractive option. Applying this advanced sensing technology in testing food samples will also overcome the problems of having to send the samples for laboratory analysis as in the case in analysis using the traditional techniques. Such screening methods can save valuable time and resources especially in fresh foods and food processing (Tothill, 2003a). To date the developments in nanomaterials and biosensor fabrications technology is moving rapidly with new and novel nanobiorecognition materials being developed which can be applied as the sensing receptors for mycotoxins analysis. Advances in transducer technology at the micro/nanoscale has resulted in more emerging devices for multiplex analysis and nanotracking systems which are feasible to fulfil the rapid monitoring and control need of the food chain. Micro and nano systems developed for logistic food surveillance by means of 
implementation of multisensing systems is also revolutionising food tracking. New and emerging advances in lab-on-a-chip devices, microarray and nanotechnology are also having a high impact on developing biosensors with new capabilities which can be applied for to mycotoxins analysis. To insure optimum quality is delivered to the consumer rapid assessment using cost-effective measurements is required in the food industry. However, the technology is still developing and it may be a while before real commercial products are widespread on the market. An overview of the emerging bio-sensing technologies available to date and nanotechnology based materials and transducers which are being developed and can be applied for mycotoxins analysis will be covered in this manuscript.

\section{Advantages of using nanomaterials in biosensors}

Nanotechnology has the potential to improve food quality and safety significantly through the use of advanced micro and nanosensors and tracking systems. Nanotechnology is research at the interface between chemistry, biology, material science, physics and engineering where ultra precision engineering can be combined with nanostructured materials and molecular manipulation to produce novel devices. The national nanotechnology Initiative (NNI) defines nanotechnology as "Research and technology development at the atomic, molecular or macromolecular scale leading to the controlled creation and use of structures, devices and systems with a length scale of 1-100 nanometers (nM) (McNeil, 2005). Interest in nanotechnology relies on the new properties that materials exhibit when reduced to the nanometer scale compares to the bulk materials. Lab-on -a-chip devices are examples of micro/nanotechnology systems approaches which can be used for the analysis of food contaminants such as mycotoxins for on- site analysis. These devices can be cost effective and highly beneficial for the food industry in ensuring high safety and quality of the food and also for risk assessment and management. The use of nanomaterials and structures such as semiconductors and conducting polymer nanowires, and nanoparticles (carbon nanotubes, silica nanoparticles, dendrimers, noble metals nanoparticles, gold nanoshells, superparamagnetic nanoparticles quantum dots, polymeric nanoparticles) for biosensor applications is expanding rapidly. Figure 1, show examples of some nanoparticles used for sensors applications. To date many comprehensive review articles have been published in this area (Katz and Willner, 2004; Katz et al., 2004; Willner et al., 2007; Kerman et al., 2008; Tothill, 2009). 
The application of nanotechnology in biosensors can range from the transducer device, the recognition ligand, the label and the running systems (e.g instruments). Their application in sensor development has been due to the excellent advantages offered by these materials in miniaturisation of the devices, signal enhancements which result in high precision and accuracy and also amplification of signal by the use of nanoparticles as labels. These can increase sensitivity of the final devices and also allow the fabrication of multiplex sensor systems such as high density protein arrays (Jain, 2004). The high surface to volume ratio offered by nanomaterials makes these devices very sensitive and can allow a single molecule detection which is very attractive in contaminant monitoring such as toxins. Small size advantages also include; higher speeds, electrons have smaller distance to travel; lower power, lower voltages are needed to achieve the same field in the semiconductor; higher component densities and chip functionality such as multi analysis capability. The use of nanowire transducers can also offer greater sensitivity in affinity sensors development (Woolley et al., 2000; Wang et al., 2005). The use of luminescent nanocrystals (Quantum dots) as molecular labels to replace fluorophores has created new applications for nanomaterials in labelling and visualisation. These nanocrystals can be attached to antibodies and other molecules to detect different analytes at the same time (multiplex sensing). Quantum dots show distinct advantages over other markers due to their spectroscopic properties and narrow emission peaks and therefore their use in multiplexed analysis is increasing. Their high emission quantum yield result in improved signal / noise ratio and therefore decrease false readings (negative and positive). To date the use of quantum dots in sensing application have been expanding across a diverse range of analysis (Goldman et al., 2004; Medintz et al., 2005; Jorge et al., 2007). However, the stability of quantum dots needs improving, reduce aggregation in use conditions and also reduce cost as they are expensive to date.

Metal nanoparticles have been applied in biosensors as marker tags to replace enzymes as the label. Striping voltammetry as an electrochemical technique can be applied to detect the metal nanoparticles directly making the assay simple to perform. Gold and silver nanoparticles can be used in these methods including different inorganic nanocrystals (e.g. $\mathrm{ZnS}, \mathrm{PbS}, \mathrm{CdS}$ ) for analytes detection. The unique physical and chemical properties of nanoparticles such as colloidal gold can provide excellent application in a wide range of biosensing techniques (Rosi and Mirkin, 2005). Several products are available on the market such as Oxanica (UK) Quantum dots and MultiPlxBeads ${ }^{\mathrm{TM}}$ from Crystalplex Corp., USA. 
Nanoparticles can also be exploited in conductivity based sensors where they can induce a change in the signal upon the attachment of the nanoparticles- antibody tagged with the captured antigen on the sensor surface. The application of gold nanoparticles for mycotoxin analysis has been recently reported. Xiulan and co-workers have developed an immunochromatographic method for $\mathrm{AFB}_{1}$ detection using a combination of an antibody with a nanogold conjugate probe (Xiulan et al., 2005). Liu at al. (2006) used gold nanoparticles as tags in an assay design for aflatoxin $\mathrm{B}_{1}$ analysis. Both of the above papers reported good sensitivity for pure toxins. Gold nanoparticles are easy to functionalise and used for antibody immobilisation and then applied in the Enzyme Linked Immunosorbent assay (ELISA) test on the surface of the electrode. We have applied gold nanoparticles for mycotoxin analysis to enhance the enzyme signal achieved on the surface of the electrochemical transducer (unpublished data).

The development of micro/nanosensor devices for toxins analysis is increasing due to their extremely attractive characteristics for this application. Their novel electron transport properties make them highly sensitive for low level detection (Wang, 2005, Logrieco et al., 2005). The multiplex analysis capability is also very attractive for multi biomarker analysis. These devices are also benefiting from the advances taking place in the development of what is referred to "nanotools" which include; advanced fabrication techniques; analysis and metrology instruments; software for nanotechnology research and development; the use of lithography, chemical vapor deposition (CVD), 3-D printing, and nanofluidics.

\section{Biosensors as diagnostics tools}

A biosensor is defined as a bioanalytical device incorporating a molecular recognition element associated or integrated with a physicochemical transducer (Tothill \& Turner, 2003). To date there are five types of transducers used in biosensor devices and these include; electrochemical, optical, mass sensitive, calorimetric and magnetic transducers. The official IUPAC definition states 'A biosensor is a self-contained integrated device, which is capable of providing specific quantitative or semi-quantitative analytical information using a biological recognition element (biochemical receptor) which is retained in direct spatial contact with a transduction element'(Thévenot et al., 1999). Figure 2, show the concept of constructing a biosensor device where a biorecognition material is selected and then 
immobilised on the chosen sensor platform surface. The assay is then developed and optimised and this is then combined with the instrument which will produce the digital signal. The use of these devices allow the capability of analysing food and feed samples on-site such as on the farm or at the food factory (Tothill, 2001). That is because biosensors have the advantages over traditional methods of being, simple, rapid, cost effective and portable devices that are sensitive and specific for the target analyte e.g the mycotoxin. These devices can also be designed to be disposable for single use, reusable for several analyses or for continuous monitoring. A range of biosensors have now been developed and reported in the literature for mycotoxins analysis some of which have the capability of multi array mycotoxins diagnosis (multiplexing capabilities). Sample preparation can usually be incorporated as part of the sensor procedure system. Some of the extraction and clean-up procedures may be similar to the procedures used for HPLC or GC analysis especially if the samples are of solid foods nature. Some sensors have been developed to be applied directly for liquid samples without the need for extraction of the sample. To date sensors can be designed to handle the sample through the inclusion of a microfluidic system or membrane separation system as part of their design for extracted food samples handling.

\section{Molecular Recognition element}

In order to recognise specifically the mycotoxin of interest, the optimal recognition materials (sensing receptor) need to be integrated on the surface of the sensor. This is especially important for small molecular weight toxins with diverse structural similarities as the sensitivity and specificity of the sensing molecules will play an important role in the success of the sensor device. The range of the different types of sensing receptors that can be used as sensing layers in biosensors has been reviewed recently (Zourob, 2010). Similarly a range of molecular recognition receptors have been developed for mycotoxins recognition and detection. The most widely used is the antibody molecule, which provides the specificity and sensitivity required for low level of toxins detection. More recently synthetic (artificial) molecular recognition elements have been designed and fabricated as affinity materials and applied for analyte detection and analysis. This type of materials can include nanomaterials and membrane structures and can comprise molecular imprinted polymers (MIPs), aptamers, phage display peptides, binding proteins and synthetic peptides as well as some metal oxides materials (Tothill et al., 2001, Shaikh et al., 2005, Collett et al., 2005, Tothill, 2010a). A recent review on the development of novel materials for mycotoxin analysis has been reported by Maragos (2009). 
Antibodies (monoclonal and polyclonal) or antibody fragments have been used in the development of immunosensors targeting mycotoxins analysis. Polyclonal antibodies can be raised against mycotoxins as long as the molecular mass and the structure of the mycotoxin is able to induce specific and high affinity antibody production. The use of monoclonal antibodies however, results in more specific tests. Drawback is that monoclonal antibodies are more difficult to maintain and can be more expensive than polyclonal antibodies. A range of antibodies are now commercially available for most mycotoxins. Many ELISA tests, dipsticks and assays have been developed and are commercially available for a range of mycotoxins using antibodies (Goryacheva and De Saeger, 2011). Antibody fragments and molecular-engineered antibodies have been developed for biosensor applications (Zourob, 2010). The use of direct and combinatorial mutagenesis has been applied to enhance the affinity and selectivity of recombinant antibodies. However, due to lack of stability of the antibody molecule, this can make it unsuitable for long term biosensor device storage and can hinder the wider application and also the commercialisation in some instances. Replacing natural biomolecules with artificial receptors or biomimics has therefore become an attractive area of research in recent years (Tothill, 2003). Due to our vast know-how to date in how natural molecules such as the DNA and the protein molecules are created and fold in their three dimensional structure, we have been recently able to design new biomimics to solve the problems faced from applying nature molecules in the sensors and diagnostics. The advantages of using these new and novel molecules and nanomaterials is that they are robust, more stable and cheap to produce in some cases since they can be made using wet chemistry and can be modified easily to aid immobilisation on the sensor surface and also to add labels as the marker for detection. They also obviate the use of animals in the production of affinity receptors as is the case of polyclonal antibody production.

The use of phage display technology to screen libraries for specific receptor molecules is being rapidly applied in the diagnostics arena. This is to identify specific peptide sequences with affinity towards target analytes (Oyama et al., 2003, McGuire et al., 2004 a,b, Chang et al., 2005, Shukla and Krag, 2005). However, a large number of the literature in this area is focusing mainly on medical application purposes. There are many literature were peptides have been specifically synthesised to target specific molecules such as estradiol (Giraudi et al., 2003), estrogens (Tozzi et al., 2002) and aflatoxins (Tozzi et al., 2003). Recent work at Cranfield University used a computational approach for the design of peptide receptors for 
aflatoxin $\mathrm{M}_{1}$ and ochratoxin A respectively (Tothill, 2010a). By using molecular modelling software, peptide receptors were designed and then synthesised for these target toxins. Affinities of the peptides were confirmed using SPR sensor platforms. Peptides can be chemically synthesised in large quantities once the optimal sequence with the required affinity has been identified. Peptides as receptors for biosensors application have been reviewed recently (Tothill, 2010a).

Molecular-imprinted polymers (MIP) have been developed and synthesised also as sensing receptors. The process use organic polymers to specifically imprint target molecule to produce synthetic materials that can be used for affinity recognition of that target molecule after removing the target compound from the polymer (Mosbach, 1994, Mosbach and Ramstrom, 1996). Molecular-imprinting polymerisation has been the focus of intense research interest in recent years and been developed for the preparation of selective separation materials and as sensing layers in sensor devices (Batra \& Shea, 2003; Piletsky et al., 2006). MIPs are usually produced by forming highly cross-linked organic polymer around the molecule of interest (analyte target/ template) therefore any impurities will produce less specific affinity media (Tozzi et al., 2003). For mycotoxins applications MIPs have mainly been used as clean up media for sample extraction and pre-treatment and also as sensing receptors (Weiss, 2003; Yu and Lai, 2005; Urraca et al., 2006). At Cranfield University a diverse research has taken place to develop MIPs using molecular modelling software for mycotoxin analysis. As an example Turner et al., (2004) developed a MIP for ochratoxin A extraction and analysis using a quartz crystal microbalance (QCM) sensor which showed a detection limit in the range of 50 $-100 \mu \mathrm{g}^{-1}$ range. A range of other MIPs have also been developed towards ochratoxin A and used for sample extraction and clean-up from red wine (Jodlbauer et al., 2002; Maier et al., 2004). Further, MIPs developed towards fumonisin B (De Smet et al., 2009) and T-2 toxin (De Smet et al., 2010) showed to be an alternatives for clean-up and pre-concentration of these toxins in food matrices. The construction of peptide receptors based on the molecular imprinting approach has also been carried out (Giraudi et $a l$, 1999, 2003) where amino acids are used as the functional monomers for the polymerisation process around the template. The use of molecular modelling has been applied for the selection of the highest affinity monomers to be used in the construction of MIPs (Chianella, et al., 2002; 2003). The major disadvantage is that MIPs require a template (pure form of the analyte) to produce the synthetic polymer which can in cases be a significant cost. The use of template analogues is a cheaper option, but this may reduce the specificity of the MIPs 
produced. Also their applications as sensing layers in sensor devices have been limited due to their low specificity and sensitivity when compared to the antibody molecule.

Aptamers (derived from the latin aptus, meaning 'to fit') are synthetic oligonucleotide ligands (DNA or RNA). These can be selected from combinatorial libraries of synthetic nucleic acids that have specific affinity for a target molecule. Using synthetic evolution of ligands (SELEX) process, aptamers can be selected from random pools and then chemically produced (Ulrich et al., 2001, Cerchia et al., 2002). These can be selected against drugs, proteins, toxins and other analytes and used as receptors in diagnostics and sensor devices (Brody and Gold, 2000; Mascini et al., 2001; O'Sullivan, 2002, Clark and Remcho, 2002). Interest in the use of aptamers increased in recent years especially for use in the area of diagnosis as sensing molecules (Luzi et al., 2003, Tombelli et al., 2005). An aptamer specific for ochratoxin A has been reported recently by Cruz-Aguado and Penner (2008a, b). The authors used fluorescence polarization immunoassay where the tracer molecule was fluorescently labelled oligonucleotides and the assay was reported to achieve good detection limits. The same aptamer was also implemented in an SPE column for samples extraction, before analysis. Detection of aptamer-protein interactions using label free electrochemical detection system based on impedance spectroscopic transduction has been reported (Rodriguez et al., 2005).

The use of bilayer lipid membrane as the sensing layer for mycotoxin detection has been reported by Andreous \& Nikolelis (1998), Siontorou et al., (2000) and Gilbert and Vargas (2003). In principle many ion channel proteins have binding sites for toxins and drugs and therefore have the ability to be used as the sensing materials in sensor devices. The interaction of the toxin with the bilayer induces the opening of the channels in the lipid layer allowing ionic eluent to pass through. Measurement of ionic conductance changes or impedance through the ion channels can be used to detect the level of the toxins. The method has a rapid analysis time (response time of 15 seconds) and the lipid membranes can be reused for many times. A limit of detection of $0.016 \mu \mathrm{g} \mathrm{L}^{-1}$ was reported for aflatoxin M1 (Gilbert and Vargas, 2002; Siontorou et al., 2000). A review on how the sensing system works is reported by Sugawara et al., 2002 and Phung et al, 2011. The bilayers suffer from low stability and are more difficult to implement in sensor devices when compared to other receptors. 


\section{$\underline{\text { Transducers }}$}

A transducer is the device that converts the recognition signal events into a digital signal which can be electrochemical (amperometry, potentiometry, conductimetry/impedimetry), optical (colorimetry, fluorescence, luminescence, interferometry, spectroscopy of optical waveguides and surface plasmon resonance), calorimetric (thermistor), mass sensitive (piezoelectric/acoustic wave) or magnetic (Tothill and Turner, 2003). Electrochemical transducers are the most widely used in sensor technology, however, recently optical and piezoelectric sensors have gained popularity and their use in biosensor development is expanding rapidly. The main reason for this is that most electrochemical systems still requires the use of a label molecule such as enzyme where a substrate mixture needs to be added for the assay results to be monitored, this with the exception of conductimetry/impedimetry transducers. In an optical transducer such as SPR and waveguides systems the binding event between the receptor used on the sensor surface and the analyte can be detected directly. In a piezoelectric/acoustic system the change in mass due to the binding between the analyte and the receptor on the sensor can also be monitored directly. A range of sensors have been developed for mycotoxins analysis an example of which is listed in Table 1 (Tothill, 2011). Recent developments also reported by Zhilei et al., 2011 and Maragos, 2011.

Electrochemical biosensors have been developed for mycotoxins analysis as portable, simple, easy to use, cost effective, and highly sensitive devices and when combined with a small handheld instrument produce a very attractive assay system. The sensors can then be used for on-site mycotoxins analysis that can be conducted by non expert personals. Many of these sensors are based on amperometric transducers and a screen-printed disposable electrode. This type of biosensor is similar to the glucose biosensor which has been used widely throughout the world for glucose testing in the home, bringing diagnosis to on- site analysis. Two types of electrochemical sensor principles have been reported in the literature for mycotoxins analysis and these include either based on enzyme inhibition as a total sample toxicity assay (Moressi et al., 1999) or based on affinity sensors where a specific receptor is used to detect the target toxin. Affinity based sensors however, offer great selectivity and sensitivity for mycotoxins analysis and most are based on the use of an ELISA assay conducted on the electrode surface. The sensors comprise three electrodes configuration with working, reference and a counter (auxiliary) electrode with the antibody (or the toxin) is 
labelled with an enzyme (horseradish peroxidase or alkaline phosphatise) that is able to produce an electro-active signal when catalysing the substrate mixture and detected the sensor surface. Currently, immunosensors based on electrochemical transducer are widely reported in the literature for mycotoxin analysis. Most of these sensors are able to achieve very good sensitivity and specificity for the target mycotoxin (Micheli et al., 2005; Piermarini et al., 2006; Parker \& Tothill, 2009). The use of gold as the working electrode has been expanding in recent years since it is more stable against oxidation and easy to functionalise for covalent immobilisation giving better assay reproducibility and also less prone for nonspecific binding when compared to carbon electrodes (Abdul Kadir \& Tothill, 2010; Heurich et al., 2011). Change in the electrochemical properties (conductivity or capacitance) on the sensor surface due to the antibody antigen interaction can also be used as the detection principle. These devices are very attractive as label free techniques, but they can be less sensitive for small molecules such as mycotoxins. Hence, the use of nanomaterials as tags will improve the sensitivity of these devices.

Some of the first biosensors developed for mycotoxins analysis used optical transducers. Maragos \& Thompson (1999) developed a fibre-optics device for the detection of aflatoxin $\mathrm{B}_{1}$ based on evanescent waves. An optical sensor for aflatoxins based on fluorescence polarization was also reported by Nasir \& Jolley (2002). The use of optical transducers in biosensors development have been reviewed recently (Ligler and Taitt, 2008; Borisov and Wolfbeis (2008). Other optical biosensor platforms that exploit grating coupler, waveguides, resonant mirror and surface plasmon have been widely used for analyte diagnosis and bimolecular interaction events studies. The BiaCore ${ }^{\mathrm{TM}}$ biosensor instrument (GE Health Care, USA) is the most widely used SPR based optical transducer system as a biosensor platform. Other companies have also produced SPR based sensors such as Texas Instruments (SPREETA range), Nippon Laser, IBIS Technologies B.V (IBIS-iSPR), and most recently Sierra sensors GmbH (Hamburg, Germany). The use of SPR for mycotoxins detection has been reported for several types of toxins (Mullett et al., 1998; Daly et al., 2000; Gaag et al., 2003; Tudos et al., 2003). However, optical biosensors have the disadvantage of being more expensive than other biosensor technologies and also are more suitable in most cases for lab based analysis when compared to electrochemical sensors (Tothill, and Turner, 2003).

Piezoelectric/ acoustic sensors such as quartz crystal microbalance (QCM) and surface acoustic devices (SAW) are also classified as being label-free technology. Piezoelectric 
sensors comprise of a quartz crystal coated with gold electrode and used as a microbalance sensitive for a change in the mass on the sensor surface (Cooper and Singleton, 2007). QCM devices have been used for a wide range of applications in the medical field (Uludag and Tothill, 2010). However, OCM immunosensors are potentially more suitable for detection of large molecular weight compounds since the sensing principle is mass deposition dependent. Due to the low molecular mass of mycotoxins it is difficult to produce a sensitive sensor based on direct capture, but the use of competitive assay format with an amplification system such as the use of nanoparticles may achieve an acceptable detection limit. Hauck et al., 1998, reported on the development of an ochratoxin A based QCM sensor that gave a linear range of $2-100 \mu \mathrm{g} \mathrm{L}^{-1}$. Other researchers such as Tsai and Hsieh (2007), reported the development of a QCM sensor for ochractoxin A which exhibited a detection limit of $16.1 \mathrm{ng}$ $\mathrm{ml}^{-1}$ in buffer. Jin et al., (2009), developed a QCM based sensor for aflatoxin $\mathrm{B}_{1}$ detection using a biocatalysed deposition amplification system and achieving a detection of 0.01-10.0 $\mu \mathrm{g} \mathrm{L}^{-1}$. More advanced QCM devices are now available on the market as an example is the QCMA 1 Sensor instrument (Sierra Sensors GmbH, Hamburg, Germany) which is a fully automated instrument. This is being used at Cranfield University (England, UK) to develop a range of affinity based sensors for a range of analysts.

Cantilever based sensors have also been introduced for analytes detection recently. Affinity interaction between the antibody on the surface of the cantilever and the analyte is detected through the amount of bending of the sensor due to mass change which is detected as a change in the resonant frequency (Baller et al., 2000, Hansen and Thundat, 2005). Microfabricated cantilever has been produced as a promising technology for bio-sensing application (Waggoner and Craighead, 2007) and can operate either in static mode or dynamic mode and has been used for pathogens detection (Nugaeva et al., 2007). For mysotoxins analysis, so far no work has been reported in the literature.

\section{Micro /Nano electrodes Arrays}

The development of micro/nanosensor devices for toxins analysis is increasing due to their extremely attractive characteristics for this application. In principle these devices are miniature transducers fabricated using conventional thin and thick film technology. Their novel electron transport properties make them highly sensitive for low levels detection 
(Wang, 2005, Logrieco et al., 2005). The multiplex analysis capability is also very attractive for multi biomarker analysis. Micro/nanoelectrodes can be classified as small electrodes in which at least one dimension is in the $\mu \mathrm{m}$ or $\mathrm{nm}$ range respectively. These can also be fabricated using different materials such as platinum, gold, iridium and carbon on silicon wafers. Microelectrode arrays (MEA) have been fabricated to produce miniaturized electrochemical sensors (Berduque et al., 2007; Huang et al., 2009). Different shapes and sizes of these electrodes have been fabricated using standard deposition, etching, lithography and photolithography techniques, including microdisk electrodes (Aguiar et al., 2007), microband electrodes (Ordeig et al., 2008), interdigitated electrodes and three dimensional MEA (Xu et al., 2008) (Figure 3). The devices can be based on macro type of transducers such as receptor spots on glass slide or can be easily fabricated using screen-printing technology with multi working electrode array. In order to develop practical devices for commercial developments problems of binding between heterogeneous antigens and antibodies used in the sensor assays and also the high background signals need to be eliminated and controlled. Multi toxins detection (e.g Mycotoxins) in foods can be conducted using single micro/ nanoelectrode array chip with high sensitivity and rapid analysis time. The use of micro/nanoarrays for analysis applications in foods can produce highly sensitive sensors.

Multi mycotoxins detection has also been reported in the literature using different sensor platforms combined with multi ELISA assays. Therefore, multi toxins can be detected on a single microelectrode array chip with multi-array working electrode, where different antibody is immobilised to detect a specific mycotoxin. Micro/nanoelectrodes arrays have unique properties which include; small capacitive charging current and faster diffusion of electro active species which will result in an improved response time and greater sensitivity (Berduque et al., 2007). The use of lab-on-a-chip is expanding in all areas of analysis due to the advantages of using small samples to analyse several markers/ toxins, i.e offer high throughput analysis (Tothill, 2010b). These types of devices will be attractive for mycotoxin analysis since several toxins may exist in the same food or feed sample. Examples are the electrochemical assay developed by Piermarini et al., (2007) using a 96 well screen printed microplate to detect aflatoxin B1 in corn samples. Detection was carried out using alkaline phosphatase as the label enzyme with the array used to detect the toxins in several samples simultaneously. Other examples of multi mycotoxins analysis sensors include those reported by Ngundi et al., (2005 \& 2006) using a fluorescence labelled antibody with a sensor arrays 
to detect ochratoxin A and deoxynivalenol. Also Gaag et al (2003) developed an SPR biosensor array to monitor aflatoxin B1, and deoxynivalenol. However, no real samples were analysed using this sensor. Ligler et al., (2003) reported on the use of biosensor consisting of a patterned array of capture antibody immobilised on planar waveguide. A fluorescent assay is then performed and the spots are captured using a CCD camera. Several authors reported the use of competitive immunofluorescent assays on a biosensor array for the simultaneous detection of several mycotoxins such as aflatoxin B1, fumonisin, ochratoxin A and deoxynivalenol (Ligler et al., 2003; Sapford et al., 2006). Recently, Bayer Technology Services $\mathrm{GmbH}$ ), have developed a mycotoxin biochip platform based on planar waveguide technology, which is able to analyse multiple mycotoxins based on fluorescently labelled antibodies and consist of a reader and a lab-on a-chip cartridge.

We have developed an electrochemical microarray with 35 arrays and which was used for the detection of aflatoxin $M_{1}$ (Parker et al., 2009) (Figure 4). Each array consisted of 35 microsquare electrodes with $20 \mu \mathrm{m} \times 20 \mu \mathrm{m}$ dimensions and edge-to-edge spacing of $200 \mu \mathrm{m}$ (an electrode width to spacing ratio of 10). These dimensions and spacings were chosen to avoid overlapping diffusion layers between neighboring electrodes in the array. The whole microarray was used to immobilise the antibody for aflatoxin $\mathrm{M}_{1}$ analysis with very sensitive detection limit achieved ( $8 \mathrm{ng} \mathrm{L}^{-1}$ in milk) using amperometry as the detection system. This has now been also used for aflatoxin B1 and fumonisins detection (unpublished data). The use of microarrays for mycotoxin analysis is still progressing and as shown above it can produce very highly sensitive sensors for mycotoxin analysis.

\section{Challenges facing technology development}

The application of nanotechnology in the development of nanodevices for sensing faces many challenges as it is still developing and therefore many issues and problems may still need to be resolved in order to produce successful commercial products that can compete with traditional methods of mycotoxins analysis. Also the complexity of molecular structures of the toxins and the wide range of concentrations need to be detected, coupled with the complexity of the food matrices are some of the bio-analytical challenges facing the application of nanodevices for food analysis. The stability of some nanomaterials such as quantum dots still needs improving, reduce aggregation in use conditions and also reduce 
their cost. Problems associated with sample treatment, delivery to the nanosensor devices still require extensive investigation to develop a better microfludic systems and informatics tools for signal output. Currently a lot of work is being carried out with huge investments from industry and governments to develop nanosensors and nanosystems targeting improved detection (sensitivity and selectivity), multiplexing analysis (analysing several analytes at the same time), rapid (short analysis time), on-site in field analysis (portable devices), and cost effective (low cost compared to lab based analysis).

Concerns regarding the use of nanotechnology in this particular application are limited due to low exposure of the food since it is reduced to the wider issue of toxicity risks for humans and the environment after the disposable of these devices and materials. We should however, take the signs associated with the toxicity of nanoparticles very seriously and ensure and control there safe disposal, especially the potential risks posed by engineered nanoparticles, until further studies proof otherwise.

\section{Conclusions}

There is a worldwide interest in the field of biosensors and their developments for health, food and environmental analysis. Hence, innovation in this area is taking place at all levels of the technology including the sensing receptor, the transducer and the accompanying electronics and analysis software and microfluidics. As we progress from single analyte testing to multianalyte analysis, miniaturisation and novel materials such as nanoparticles and micro/nano based transducers are playing a major part in producing highly sensitive and cost effective devices. A range of sensors are being developed for mycotoxins based on the above technologies which can be applied in the farm or the factory and operated by unskilled personnel. Current trends to produce chip-based micro/nanoarrays for multi mycotoxins analysis are challenging but possible and it will have significant impact on risk assessment testing. The use of nanoparticles such as gold, silver, metal oxides and quantum dots assay developments will enhance the capability of the biosensor technology for mycotoxins analysis. Early and sensitive detection will aid in eliminating these toxins from entering the food chain and preventing ill health and protecting life. Therefore these rapid technologies need to be developed further using appropriate funding to move the technology from research to commercial products. 


\section{Acknowledgement}

The author acknowledges the European Commission through the (Project FP6-IST1-508774IP "GOODFOOD: Food safety and quality with Microsystems technology”), DuPont UK Limited and Sierra Sensors GmbH for financial and collaborative research support.

\section{References}

Abdul Kadir, M.K and Tothill, I.E., 2010. Development of an electrochemical immunosensor for fumonisins detection in foods. Toxins 2: 382-398.

Adanyi, N., Levkovet, I, A., Rodriguez-Gil, S., Ronald, A., Varadi, M., and Sdenro, I., 2007. Development of immunosensor based on OWSL technique for determining of Aflatoxin B1 and Ochratoxin A. Biosensors and Bioelectronics 22: 797-806.

Aguiar, F.A., Gallant, A.J., Rosamond, M.C., Rhodes, A., Wood, D. and Kataky, R., 2007. Conical recessed gold microelectrode arrays produced during photolithographic methods: Characterisation and causes. Electrochemistry Communications 9: 879-885.

Alarcon, S.H., Palleschi, G., Campahnone, D., Pascale, M., Visconti, A., Barna-Vetro, I., 2006. Monoclonal antibody based electrochemical immunosensor for the determination of Ochratoxin A in wheat. Talanta 69: 1031-1037.

Ammida, N.H.S., Micheli, L., Palleschi, G., 2004. Electrochemical immunosensor for determination of aflatoxin B1 in barley. Analytica Chimica Acta 520: 159-164.

Andreous, V.G. and Nikolelis, D.P., 1998. Flow injection monitoring of aflatoxin M1 in milk and milk preparations using filter supported bilayer lipid membranes. Analytical Chemistry 70: 2366-2371.

Badea, M., Micheli, L., Messia, M.C., Candigliota, T., Marconi, E., Mottram, T., VelascoGarcia, M., Moscone, D. and Palleschi. G., 2004. Alfatoxin M1determination in raw milk using a flow-injection immunoassay system. Analytica Chimica Acta 520: 141-148.

Baller, M.K., Lang, H.P., Fritz, J., Gerber, C., Gimzewsk, J.K., Drechsler, U., Rothuizen, H., Despont, M., Vettiger, P., Battiston, F.M., Ramseyer, J.P., Fornaro, P., Meyer, E. and Guntherodt, H.J., 2000. A cantilever array-based artificial nose. Ultramicroscopy 82: 1-9.

Batra, D. and Shea, K.J., 2003. Combinatorial methods in molecular imprinting. Current Opinions in Chemical Biology 7: 434-442.

Berduque, A., Lanyon, Y.H., Beni, V., Herzog, G., Watson, Y.E., Rodgers, K., Stam, F., Alderman, J. and Arrigan, D.W.M., 2007. Voltammetric characterisation of silicon-based 
microelectrode arrays and their application to mercury-free stripping voltammetry of metal ions. Talanta 71: 1022-1030.

Borisov, S. M. and Wolfbeis, O. S., 2008. Optical Biosensors. Chemical Revews 108: 423461.

Brody, E.N. and Gold, L., 2000. Aptamers as therapeutic and diagnostic agents. Journal of Biotechnology 74: 5-13.

Carlson, M.A., Bargeron, C.B., Benson, R.C., Fraser A.B., Philips, T.E., Velky J.T., Groopman, J.D., Strickland, P.T. and Ko, H.W., 2000. An automated handheld biosensor for aflatoxin. Biosensors and Bioelectronics 14: 841-848.

Cerchia, L., Hamm, J., Libri, D., Tavitian, B., and de Franciscis, V., 2002. Nucleic acid aptamers in cancer medicine. FEBS 528: 12-16.

Chang, C.Y., Abdo, J., Hartney, T. and McDonnell, D.P. 2005. Development of peptide antagonists for the androgen receptor using combinatorial peptide phage display. Mol Endocrinol 19: 2478-2490.

Chianella, I., Lotierzo, M., Piletsky, S., Tothill, I.E., Chen, B. and Turner, A.P.F., 2002. Rational design of a polymer specific for microcystin-LR using a computational approach. Analytical Chemistry 74: 1288-1293.

Chianella, I, Piletsky, S.A., Tothill, I. E., Chen, B. and Turner, A.P. F. 2003. Combination of solid phase extraction cartridges and MIP-based sensor for detection of microcystin- LR. Biosensors and Bioelectronics 18: 119-127.

Chiavaro, E., Caccgiolo, C., Berni, E. and Spotto, E., 2005. Immunoaffinity cleanup and direct fluorescence measurement of aflatoxins B1 and M1 in pig liver: Comparison with High-performance liquid chromatography determination. Food additives and Contaminants 22: $1154-1161$.

Clark, S.L. and Remcho, V.T., (2002) Aptamers as analytical reagents. Electrophoresis 23: 1335-1340.

Collett, J.R., Cho, E.J., Lee, J.F., Levy, M., Hood, A.J., Wan, C. and Ellington, A.D. 2005. Functional RNA microarrays for high-throughput screening of antiprotein aptamers. Analytical Biochemistry 338:113-123.

Cooper, M.A. and Singleton, V.T., 2007. A survey of the 2001 to 2005 quartz crystal microbalance biosensor literature: applications of acoustic physics to the analysis of biomolecular interactions. Journal of Molecular Recognition 20: 154-184.

Cruz-Aguado, J.A. and Penner, G., 2008a. Fluorescence polarization based displacement assay for the determination of small molecules with aptamers. Analytical Chemistry 80: 8853-8855.

Cruz-Aguado, J.A. and Penner, G., 2008b. Determination of ochratoxin A with a DNA aptamer. Journal of Agricultural and Food Chemistry 56: 10456-10461. 
Daly, S. J., Keating, G. J., Dillon, P. P., Manning, B. M., O’Kennedy, R., Lee, H. A., and Morgan, R. A., 2000. Development of surface plasmon resonance-based immunoassay for aflatoxin B1. Journal of Agricultural and Food Chemistry 48: 5097-5104.

De Smet, D., Dubruel. P., Van Peteghem. C., Schacht, E. and De Saeger, S., 2009. Molecularly imprinted solid-phase extraction of fumonisin B analogues in bell pepper, rice and corn flakes. Food Additives and Contaminants Part a-Chemistry Analysis Control Exposure \& Risk Assessment 26:874-884.

De Smet, D., Monbaliu, S., Dubruel, P., Van Peteghem, C., Schacht, E. and De Saeger, S. 2010. Synthesis and application of a T-2 toxin imprinted polymer. Journal of Chromatography A 1217: 2879-2886.

Gaag, van der. B., Spath, S., Dietrich, H., Stigter, E., Boonzaaijer, G., Osenbruggen, T., and Koopal, K., 2003. Biosensors and multiple mycotoxin analysis. Food Control 14: 251-254.

Gilbert, J. and Vargas, E.A., (2003). Advances in sampling and analysis for aflatoxins in food and animal feed. Journal of Toxicology - Toxin Reviews 22: 381-422.

Giraudi, G., Giovannoli, C., Tozzi, C., Baggiani, C. and Anfossi, L. 1999. Estradiol binding synthetic polypeptides. Chemical Communication 13; $1135-1136$.

Giraudi, G., Giovannoli, C., Tozzi, C., Baggiani, C. and Anfossi, L., 2003. Molecular recognition properties of peptide mixtures obtained by polymerisation of amino acids in the presence of estradiol. Analytica Chimica Acta 481; 41-53.

Goldman, E.R., Clapp, A. R., Anderson, G. P., Uyeda, H. T., Mauro, J. M., Medintz, I. L. and Mattoussi, H., 2004. Multiplexed toxin analysis using four colors of quantum dot fluororeagents. Analytical Chemistry 76: 684-688.

Goryacheva, I.Y. and De Saeger, S., 2011. Immunochemical methods for rapid mycotoxin detection in food and feed. In: Determining Mycotoxins and Mycotoxigenic Fungi in Food and Feed (edit,: Prof. Dr. Sarah De Saeger), Woodhead Publishing Limited. ISBN; 978-185573-728-0, p 135-167.

Hansen, K.M. and Thundat, T., 2005. Microcantilever biosensors. Methods, 37: 57-64.

Hauck, S., Kosslinger, C., Drost, S. and Wolf, H., 1998. Biosensor system to determine ochratoxin A. Lebensmittelchemie 52: 158.

Heurich, M., Abdul Kadir, M. K and Tothill, I. E., 2011. Amperometric immunosensor for ochratoxin A in wine based on covalent immobilization to carboxymethylated dextranmodified gold electrode. Sensors and Actuators B: Chemical 156: 162-168.

Huang, X-J., O., Mahony, A. M. and Compton, R.G., 2009. Microelectrode arrays for electrochemistry: Approaches to Fabrication, Small 5: 776-788.

Jain, K.K., 2004. Applications of biochips: from diagnostics to personalized medicine. Current Opinion to Drug Discovery and Development. 7: 285-289. 
Jin, X. , Jin, X., Liu, X., Chen, L., Jiang, J., Shen, G. and Yu, R., 2009. Biocatalyzed deposition amplification for detection of aflatoxin B1 based on quartz crystal microbalance, Analytica Chimica Acta 645: 92-97.

Jodlbauer, J., Maier, N. M. and Lindner, W. 2002. Towards ochratoxin a selective molecularly imprinted polymers for solid phase extraction. Journal of chromatography A 945: 45-63.

Jorge, P., Martins, M.A., Trindade, T., Santos, J. L., and Farahi, F., 2007. Optical fiber sensing using quantum dots. Sensors 7: 3489-3534.

Katz, E. and Willner, I., 2004. Biomolecular-functionalized carbon nanotubes: applications in nanobioelectronics. ChemPhysChem. 5: 1085-1091.

Katz, E., Willner, I. and Wang, J., 2004. Electroanalytical and bioelectroanalytical systems based on metal and semiconductive nanoparticles, Electroanalysis 16: 19-44.

Kerman, K., Masato, S., Shohei, Y., Yuzuru, T. and Eiichi, T., 2008. Nanomaterial - based electrochemical biosensors for medical applications. Trends in Analytical Chemistry. 27: 913-947.

Khan, R. and Dhayal, M., 2008. Nanocrystalline-bioactive $\mathrm{TiO}_{2}$-chitosan impedimetric immunosensor for ochratoxin A. Electrochemical Communication. 10: 492-495.

Ligler, F.S., Taitt, C.R., Shriver-Lake, L.C., Sapsford, K.E., Shubin, Y. and Golden, J. P., 2003. Array biosensor for detection of toxins. Analytical and Bioanalytical Chemistry 377: 469-477.

Ligler, F. S. and Taitt, C. R., 2008. Optical Biosensors, Second Edition: Today and Tomorrow. Elsevier B.V., Amsterdam, The Netherlands, pp712. ISBN-10: 444531254; ISBN-13: 978-0444531254.

Liu, Y., Qin, Z., Wu, X. and Jiang, H., 2006. Immune-biosensor for aflatoxin B1 based bioelectrocatalytic reaction on micro-comb electrode. Biochemical Engineering Journal 32: 211217.

Logrieco, A., Arrigan, D. W. M., Brengel-Pesce, K., Siciliano, P. and Tothill, I.E., 2005. Microsystens technology solutions for rapid detection of toxigenic fungi and mycotoxins. $\mathrm{J}$ of Food Additives and Contaminants 22:335-344.

Luzi, E., Minunni, M., Tombelli, S. and Mascini, M., 2003. New trends in affinity sensing: aptamers for ligand binding. Trends in analytical Chemistry 22: 810-818.

Maier, N.M., Buttinger, G., Welhartiziki, S., Gaviolo, E. and Lindner, W. 2004. Molecularly imprinted polymer-assisted sample clean-up of ochratoxin A from red wine: Merits and limitations. Journal of Chromatography B 804: 103-111.

Maragos, C.M. and Thompson, V.S., 1999. Fiber-optic immunosensor for mycotoxins. Natural Toxins 7: 371-376. 
Maragos, C. M., 2009. Recent advances in the development of novel materials for mycotoxin analysis. Analytical and Bioanalytical Chemistry 395: 1205-1213.

Maragos, C.M. 2011. Detection of deoxynivalenol using biolayer interferometry. Mycotoxin Research 27:157-165.

Mascini, M., Palchetti, I., and Marraza, G. 2001. DNA electrochemical biosensors. Fresenius Journal of Analytical Chemistry 369: 15-20.

McNeil, S.E., 2005. Nanotechnology for the biologist, Journal of Leukocyte Biology 78: 585594.

McGuire, M.J., Samli, K.N., Johnston, S.A. and Brown, K.C. 2004a. In vitro selection of a peptide with high selectivity for cardiomyocytes in vivo. Journal of Molecular Biology 342: $171-182$.

McGuire, M.J., Sykes, K.F., Samli, K.N., Timares, L., Barry, M.A., Stemke- Hale, K., Tagliaferri, F., Logan, M., Jansa, K., Takashima, A., Brown, K.C. and Johnston, S.A., 2004b. A library-selected, langerhans cell-targeting peptide enhances an immune response. DNA Cell Biol. 23; 742-752.

Medintz , I.L., Uyeda, H. T., Goldman, E. R. and Mattoussi, H., 2005. Quantum dot bioconjugates for imaging, labelling and sensing. Nature Materials 4: 435 - 446.

Micheli, L., Grecco, R., Badea, M., Moscone, D. and Palleschi, G., 2005. An electrochemical immunosensor for aflatoxin M1 determination in milk using screen printed electrodes. Biosensors and Bioelectronics 21: 588-596.

Mosbach, K., 1994. Molecular imprinting, Trends in Biochemical Science 19: 9-14.

Mosbach, K., and Ramstrom, O., 1996. The emerging technique of molecular imprinting and its future impact on biotechnology, Biotechnology 14: 165-170.

Moressi, M.B., Zon, A., Fernández, H., Rivas, G. and Solis, V., 1999. Amperometric quantification of Alternaria mycotoxins with a mushroom tyrosinase modified carbon paste electrode. Electrochemical Communications 1: 472-476.

Mullett, W., Lai, E.P.C. and Yeung, J.M., 1998. Immunoassay of fumonisins by a surface plasmon resonance biosensor. Analytical Biochemistry 258: 161-167.

Myszka, D. G., 1999. Survey of the 1998 optical biosensor literature. Journal of Molecular Recognition 12: 390-408.

Nasir, M.S. and Jolley, M.E., 2002. Development of a fluorescence polarization assay for the determination of aflatoxins in grains. Journal of Agricultural and Food Chemistry 50: 31163121.

Ngundi, M. M., Shriver-Lake, L. C., Moore, M. H., Lassman, M. E., Ligler, F. S. and Taitt, C. R., 2005. Array biosensor for detection of ochratoxin A in cereals and beverages. Analytical Chemistry 77: 148-154. 
Ngundi, M.M., Shriver-Lake, L.C., Moore, M.H., Ligler, F.S., Taitt, C.R., 2006. Multiplexed detection of mycotoxins in foods with a regenerable array. Journal of Food Protection 69: 3047-3051.

Nugaeva N., Gfeller, K.Y., Backmann, N., Duggelin, M., Lang, H.P. , Guntherodt H.J. and Hegner M., 2007. An Antibody-Sensitized Microfabricated Cantilever for the Growth Detection of Aspergillus niger Spores. Microscopy and Microanalysis 13: 13-17.

Ordeig, O., Rodino, N., del Campo, J., Munoz, F.X., Nikolajeff, F. and Nyholm, L., 2008. On-chip electric field driven electrochemical detection using a poly(dimethylsiloxane) microchannel with gold microband electrodes. Analytical Chemistry 80: 3622-32.

O'Sullivan, C.K., 2002. Aptasensors - the future of biosensors? Analytical Bioanalytical Chemistry 372: 44-48.

Oyama, T., Sykes, K.F., Samli, K.N., Minna, J.D., Johnston, S.A. and Brown, K.C., 2003. Isolation of lung tumor specific peptides from a random peptide library: generation of diagnostic and cell-targeting reagents. Cancer Letters 202: 219-230.

Parker, C. and Tothill, I.E., 2009. Development of an electrochemical immunosensor for aflatoxin M1 in milk with focus on matrix interference. Biosensors and Bioelectronics 24: 2452-2457.

Parker, C., Lanyon, Y., Manning, M. Arrigan, D. W. M. and Tothill, I.E, 2009. Development of microsensor for Aflatoxin M1. Analytical Chemistry 81: 5291-5298.

Pemberton, M.R., Pittson, R., Biddle, N., Drago, G.A. and Hart, J.P., 2006. Studies towards the development of a screen-printed carbon electrochemical immunosensor array for mycotoxin: A sensor for aflatoxin B1. Analytical Letters 39:1573-1586.

Piermarini, S., Micheli, L., Ammida, N.H.S., Palleschi, G. and Moscone, D., 2007. Electrochemical immunosensor array using a 96-well screen-printed microplate for aflatoxin B1 detection, Biosensors and Bioelectronics 22: 1434-1440.

Piletsky, S., Piletska, E. V., Sergeyeva, T. A., Nicholls, I., Weston, D. and Turner, A., 2006. Synthesis of biologically active molecules by imprinting polymerization, Biopolymers and Cell 22: 63-68.

Prieto-Simón, B., Noguer, T. and Campàs, M. 2007. Emerging biotools for assessment of mycotoxins in the past decade. TrAC Trends in Analytical Chemistry 26: 689-702.

Phung, T., Zhang, Y., Dunlop, J. and Dalziel, J., 2011. Bilayer lipid membranes supported on Teflon filters: a functional environment for ion channels. Biosensors and Bioelectronics 15:3127-3135.

Rodriguez, M., Kawde, N. and Wang, J., 2005. Aptamer biosensor for label-free impedance spectroscopy detection of proteins based on recognition-induced switching of surface change. Chemical Communication 4267- 4269. 
Rosi, N. L. and Mirkin, C. A., 2005. Nanostructure and biodiagnostics. Chemical Reviews 105: 1547-1562.

Sapsford, K.E., Ngundi, M.M., Moore, M.H., Lassman, M.E., Shriver-Lake, L.C., Taitt, C.R. and Ligler, F.S., 2006. Rapid detection of food born contaminants using an Array Biosensor. Sensors and Actuators B Chemical 113: 599-607.

Schnerr, H., Vogel, R.F. and Niessen, L., 2002. A biosensor-based immunoassay for rapid screening of deoxynivalenol contamination in wheat, Food and Agriculral Immunology 14: 313-321.

Shaikh, K.A., Ryu, K.S., Goluch, E.D., Nam, J.M., Liu, J., Thaxton, C.S., Chiesl, T.N., Barron, A.E., Lu, Y., Mirkin, C.A. and Liu, C., 2005. A modular microfluidic architecture for integrated biochemical analysis, Proc. Natl. Acad. Sci. U.S.A. 102: 9745-9750.

Shukla, G.S. and Krag, D.N., 2005. Selection of tumor-targeting agents on freshly excised human breast tumors using a phage display library. Oncol Rep. 13:757-764.

Siontorou, C.G., Andreou, V.G., Nikolelis, D.P. and Krull, U.J., 2000. Flow injection monitoring of aflatoxin M1 in cheese using filter supported bilayer lipid membranes with incorporated DNA. Electroanalysis 12: 747-751.

Sugawara, M., Hirano, A., Buhlmann, P., Umezawa, Y., 2002. Design and application of ionchannel sensors based on biological and artificial receptors. Bulletins of the chemical society of Japan, 75: 187-201.

Sun, A-L., Qi, Q-A., Dong, Z-L. and Liang, K Z., 2008. An electrochemical enzyme immunoassay for aflatoxin B1 based on bio-electrocatalytic reaction with room-temperature ionic liquid and nanoparticle-modified electrodes. Sensing and Instrumentation for Food Quality 2: 43-50.

Tan,Y., Chu, Z., Shen, G-L. and Yu, R-Q., 2009. A signal-amplified electrochemical immunosensor for aflatoxin B1 determination in rice. Analytical Biochemistry 387: 82-86.

Thévenot, D.R., Toth, K., Durst, R.A. and Wilson, G.S., 1999. Electrochemical biosensors: recommended definitions and classification. Pure and Applied Chemistry 71: 2333-2348.

Thompson, V.S. and Maragos, C.M., 1996. Fiber-optic Immunosensor for the detection of fumonisin B1. Journal of Agricultural and Food Chemistry 44: 1041-1046.

Tombelli, S. Minunni, M. and Mascini, M., 2005. Analytical applications of aptamers (Review). Biosensors and Bioelectronics 20: 2424-2434.

Tothill, I.E, 2001. Biosensors Developments and potential applications in the agricultural diagnosis sector. Computers and Electronics in Agriculture, 30: 205-218.

Tothill, I.E., Piletsky, S., Magan, N. and Turner, A.P.F., 2001. New Biosensors, In: Instrumentation and sensors for the food industry (Second Edition), Erika Kress-Rogers and Cristopher J.B. Brimelow (edits). Woodhead Publishing Limited and CRC Press LLC, 760776. 
Tothill, I.E (Book Editor) 2003a. Rapid and on-line Instrumentation for Food Quality Assurance. Woodhead Publishing Limited, pp 406, ISBN: 1-85573-674-8.

Tothill, I.E., 2003b. On-line Immunochemical Assays for Contaminants Analysis, In: Rapid and on-line Instrumentation for Food Quality Assurance, Ibtisam E. Tothill (Editor). Woodhead Publishing Limited, pp 14-39, ISBN: 1-85573-674-8.

Tothill, I.E and Turner, A.P.F., 2003. Biosensors, In: Encyclopaedia of Food Sciences and Nutrition (Second Edition), Benjamin Caballero (Editor in Chief), Luiz Trugo and Paul Finglas (editors), Academic Press, pp 489-499, ISBN: 0-12-227055-X.

Tothill, I.E., 2009. Biosensors for cancer markers diagnosis, Seminars in Cell \& Developmental Biology 20: 55-62.

Tothill, I.E., 2010a. Peptides as Molecular Receptors. In: Recognition Receptors in Biosensors, (Mohammed Zourob, Editor) Springer New York, 249-274, ISBN 978-1-44190918-3.

Tothill I. E., 2010b. Application of Nanotechnology in Food Safety Assessment: NanoTracking Systems - Nanosensors, FAO Round table at Nanoagri 2010, Brazil, http://www.nanoagri2010.com/fao_mini_papers.pdf).

Tothill I.E., 2011. Emerging Bio-sensing methods for mycotoxins Analysis. In: Determining Mycotoxins and Mycotoxigenic Fungi in Food and Feed (edit, Prof. Dr. Sarah De Saeger), Woodhead Publishing Limited. ISBN; 978-1-85573-728-0, 359-384.

Tozzi, C., Anfossi, L., Giraudi, G., Giovannoli, C., Baggiani, C. and Vanni, A., 2002. Chromatographic characterisation of an estrogen-binding affinity column containing tetrapeptides selected by a combinatorial-binding approach. Journal of Chromatography A 966, 71-79.

Tozzi, C., Anfossi, L., Baggiani, C., Giovannoli, C. and Giraudi, G., 2003. A combinatorial approach to obtain affinity media with biding properties towards the aflatoxins. Analytical and Bioanalytical Chemistry 375: 994-999.

Tsai, W.-C. and Hsieh, C.-K., 2007. QCM-Based Immunosensor for the Determination of Ochratoxin A. Analytical letters, 40: 1979 - 1991.

Tudos, A. J., Lucas van den Bos, E. R., Stigter and E.C.A., 2003. Rapid surface plasmon resonance based inhibition assay of deoxynivalenol. Journal of Agriculture and Food Chemistry 51: 5843-5848.

Turner, N.W., Piletska, E.V., Karim, K., Whitcombe, M.J., Malecha, M.M., Magan, N., Baggiani, C. and Piletsky, S.A., 2004. Effect of the Solvent on Recognition Properties of Molecularly Imprinted Polymer Specific for Ochratoxin A. Biosensors and Bioelectronics 20: 1060-1067. 
Uludag, Y., and Tothill, I.E., 2010. Development of a Sensitive Detection method for Cancer Biomarkers in Human Serum (75\%) using a Quartz Crystal Microbalance Sensor and Nanoparticles amplification system. Talanta, 82: 277- 282.

Ulrich, H., Alves, M.J.M. and Colli, W., 2001. RNA and DNA aptamers as potential tools to prevent cell adhesion in disease. Braz J Med Biol Res. 34:295-300.

Urraca, J.L., Marazuela, M.D., Merino, E.R., Orellana, G. and Moreno-Bondi, M.C., 2006. Molecularly imprinted polymers with a streamlined mimic for zearalenone analysis. Journal of chromatography A 1116; 127-134.

Wang, J., 2005. Nanomaterial- based electrochemical biosensors. Analyst 130: 421-426.

Wang, W.U., Chen, C., Lin, K.H., Fang, Y., Lieber, C.M., 2005. Labelfree detection of small molecule-protein interactions by using nanowire nanosensors. Proc Natl Acad Sci USA 102: $3208-12$.

Waggoner, P.S. and Craighead, H.G., 2007. Micro- and nanomechanical sensors for environmental, chemical, and biological detection. Lab on a Chip. 7: $1238-1255$.

Weiss, R., Freudenschuss, M., Krska, R., Mizaikoff, B., 2003. improving methods of analysis for mycotoxins: molecularly imprinted polymers for deoxynivalenol and zearalenone. Food Additives and Contaminants 20: 386-395.

Willner, I., Baron R. and Willner B., 2007. Integrated nanoparticle-biomolecule systems for biosensing and bioelectronics. Biosensors and Bioelectronics 22: 1841-1852.

Woolley, A.T., Guillemette, C., Cheung, C.L., Housman, D.E. and Lieber, C.M., 2000. Direct haplotyping of kilobase-size DNA using carbon nanotube probes. Nat. Biotechnol. 18: 760763.

Xu, H., Malladi, K., Wang, C., Kulinsky, L., Song, M. and Madou, M., 2008. Carbon post microarrays for glucose sensors. Biosensors and Bioelectronics, 23: 1637-1644.

Xiulan, S., Xiaolian, Z., Jian, T., Zhou, J. and Chu, F. S., 2005. Preparation of gold-labeled antibody probe and its use in immunochromatography assay for detection of aflatoxin $\mathrm{B}_{1}$. International Journal of Food Microbiology, 99, 185-194.

Yu, J.C.C. and Lai, E.P.C., 2005. Interaction of ochratoxin A with molecularly imprinted polypyrrole film on surface plasmon resonance sensor. Reactive \&Functional Polymers 63: 171-176.

Zhilei, W.; Xiulan, S.; Zaijun, L.; Yinjun, F.; Guoxiao, R.; Yaru, H. and Junkang,L. 2011. Highly sensitive deoxynivalenol immunosensor based on a glassy carbon electrode modified with a fullerene/ferrocene/ionic liquid composite. Microchim Acta. 172:365-371.

Zourob, M., 2010. (Book Editor) Recognition Receptors in Biosensors. Springer, New York, ISBN 978-1-4419-0918-3, pp863. 
Table 1: Examples of biosensors developed for mycotoxins analysis (Tothill, 2011).

\begin{tabular}{|c|c|c|c|c|}
\hline Mycotoxin & Matrix & $\begin{array}{l}\text { Biosensor } \\
\text { principle }\end{array}$ & $\begin{array}{l}\text { Limit of } \\
\text { Detection }\end{array}$ & Reference \\
\hline Aflatoxin $B_{1}$ & $\begin{array}{l}\text { Buffer } \\
\text { Buffer } \\
\text { Maize, sorgum, } \\
\text { nuts } \\
\text { Nuts, oat } \\
\text { Buffer } \\
\text { Buffer } \\
\text { Barley } \\
\text { buffer } \\
\text { Rice } \\
\text { Human serum, } \\
\text { grape } \\
\text { Corn } \\
\text { Buffer }\end{array}$ & Electrochemical & $\begin{array}{c}3 \mu \mathrm{g} \mathrm{L}^{-1} \\
1 \mu \mathrm{g} \mathrm{L}^{-1} \\
5 \mu \mathrm{g} \mathrm{kg}^{-1} \\
\\
0.2 \mu \mathrm{g} \mathrm{kg}^{-1} \\
0.5 \mu \mathrm{g} \mathrm{L}^{-1} \\
0.5 \mu \mathrm{g} \mathrm{L}^{-1} \\
\\
0.03 \mu \mathrm{g} \mathrm{kg}^{-1} \\
0.15 \mu \mathrm{g} \mathrm{L}^{-1} \\
0.06 \mu \mathrm{g} \mathrm{L}^{-1} \\
0.05 \mu \mathrm{g} \mathrm{L}^{-1} \\
0.03 \mu \mathrm{g} \mathrm{L}^{-1} \\
0.01 \mu \mathrm{g} \mathrm{L}^{-1}\end{array}$ & $\begin{array}{l}\text { Daly et al.(2000) } \\
\text { Carlson ( 2000) } \\
\text { Nasir \& Jolley (2002) } \\
\text { Gaag et al. (2003) } \\
\text { Adanyi et al., (2007) } \\
\text { Sapsford et al., (2006) } \\
\text { Ammida et al. (2004) } \\
\text { Pemberton et al. (2006) } \\
\text { Tan et al., (2009) } \\
\text { Sun et al., (2008) } \\
\text { Piermarini et al., (2007) } \\
\text { Jin et al., (2009) }\end{array}$ \\
\hline Aflatoxin $\mathrm{M}_{1}$ & $\begin{array}{l}\text { Liver } \\
\text { Milk } \\
\text { Milk } \\
\text { Milk } \\
\text { Milk }\end{array}$ & $\begin{array}{l}\text { Optical } \\
\text { Electrochemical }\end{array}$ & $\begin{array}{c}1 \mu \mathrm{g} \mathrm{kg}^{-1} \\
0.02 \mu \mathrm{g} \mathrm{L}^{-1} \\
0.05 \mu \mathrm{g} \mathrm{L}^{-1} \\
0.039 \mu \mathrm{g} \mathrm{L}^{-1} \\
0.008 \mu \mathrm{g} \mathrm{L}^{-1}\end{array}$ & $\begin{array}{l}\text { Chiavaro et al. (2005) } \\
\text { Badea et al.(2004) } \\
\text { Micheli at al. (2005) } \\
\text { Parker \& Tothill (2009) } \\
\text { Parker et al., (2009) }\end{array}$ \\
\hline $\begin{array}{l}\text { Fumonisin } \\
\text { B1 }\end{array}$ & $\begin{array}{l}\text { Corn } \\
\text { Corn } \\
\text { Buffer } \\
\text { Buffer } \\
\text { Corn }\end{array}$ & $\begin{array}{l}\text { Optical } \\
\text { Electrochemical }\end{array}$ & $\begin{array}{l}50 \mu \mathrm{g} \mathrm{kg}^{-1} \\
10 \mu \mathrm{g} \mathrm{L}^{-1} \\
\\
50 \mu \mathrm{g} \mathrm{L}^{-1} \\
0.5 \mu \mathrm{g} \mathrm{L}^{-1} \\
5 \mu \mathrm{g} \mathrm{L}^{-1}\end{array}$ & $\begin{array}{l}\text { Mullett et al., (1998) } \\
\text { Thompson \& Maragos } \\
\text { (1996) } \\
\text { Gaag et al., (2003) } \\
\text { Sapsford et al., (2006) } \\
\text { Abdul Kadir \& Tothill } \\
(2010)\end{array}$ \\
\hline Ochratoxin A & $\begin{array}{l}\text { Cereals } \\
\text { Coffee } \\
\text { Wine } \\
\text { Wheat } \\
\text { Wine } \\
\text { Buffer } \\
\text { Wine }\end{array}$ & $\begin{array}{l}\text { Optical } \\
\text { Electrochemical } \\
\text { QCM }\end{array}$ & $\begin{array}{c}3.8 \text { to } 100 \mu \mathrm{g} \\
\mathrm{kg}^{-1} \\
7 \mu \mathrm{g} \mathrm{kg}^{-1} \\
38 \mu \mathrm{g} \mathrm{kg}^{-1} \\
0.06 \mu \mathrm{g} \mathrm{L}^{-1} \\
0.7 \mu \mathrm{g} \mathrm{L}^{-1} \\
10 \mu \mathrm{g} \mathrm{L}^{-1} \\
0.01 \mu \mathrm{g} \mathrm{L}^{-1} \\
16.1 \mu \mathrm{g} \mathrm{L}^{-1}\end{array}$ & $\begin{array}{l}\text { Alarcon et al., (2006) } \\
\text { Prieto- Simon et al., } \\
\text { (2007) } \\
\text { Khan \& Dhayal (2008) } \\
\text { Heurich et al., (2011) } \\
\text { Tsai and Hsieh (2007) }\end{array}$ \\
\hline Deoxynivalenol & $\begin{array}{l}\text { Wheat } \\
\text { Wheat } \\
\text { Buffer } \\
\text { Oats }\end{array}$ & Optical & $\begin{array}{l}2.5 \mu \mathrm{g} \mathrm{L}^{-1} \\
2.5 \mu \mathrm{g} \mathrm{L}^{-1} \\
0.2 \mu \mathrm{g} \mathrm{L}^{-1} \\
50 \mu \mathrm{g} \mathrm{kg}^{-1}\end{array}$ & $\begin{array}{l}\text { Schnerr et al., (2002) } \\
\text { Tudos et al., (2003) } \\
\text { Ngundi et al., (2006) }\end{array}$ \\
\hline
\end{tabular}


Figure 1: Examples of nanoparticles used in sensors developments.
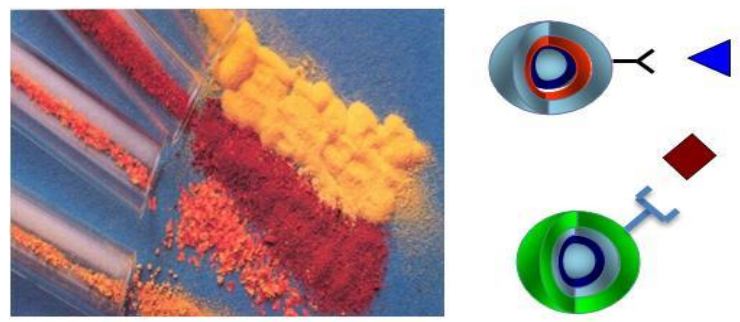

Quantum Dots

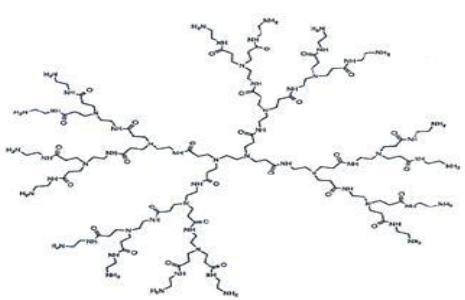

Dendrimer
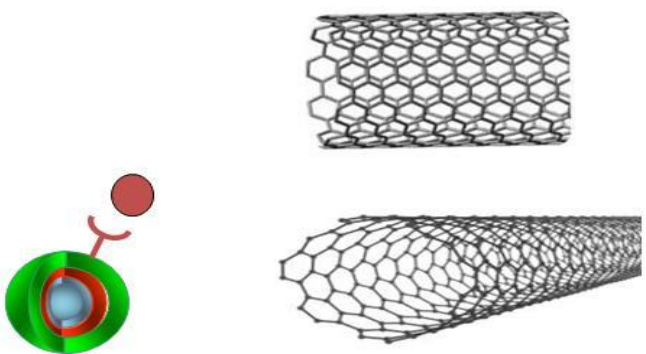

Carbon nanotubes
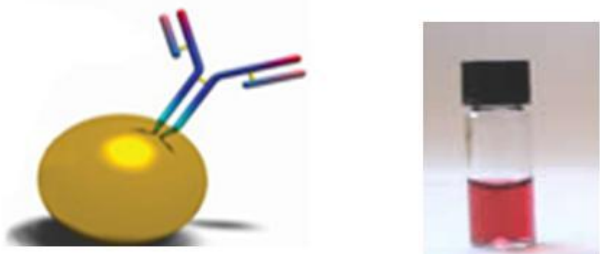

Gold nanoparticles 
Figure 2: Biosensor construction.
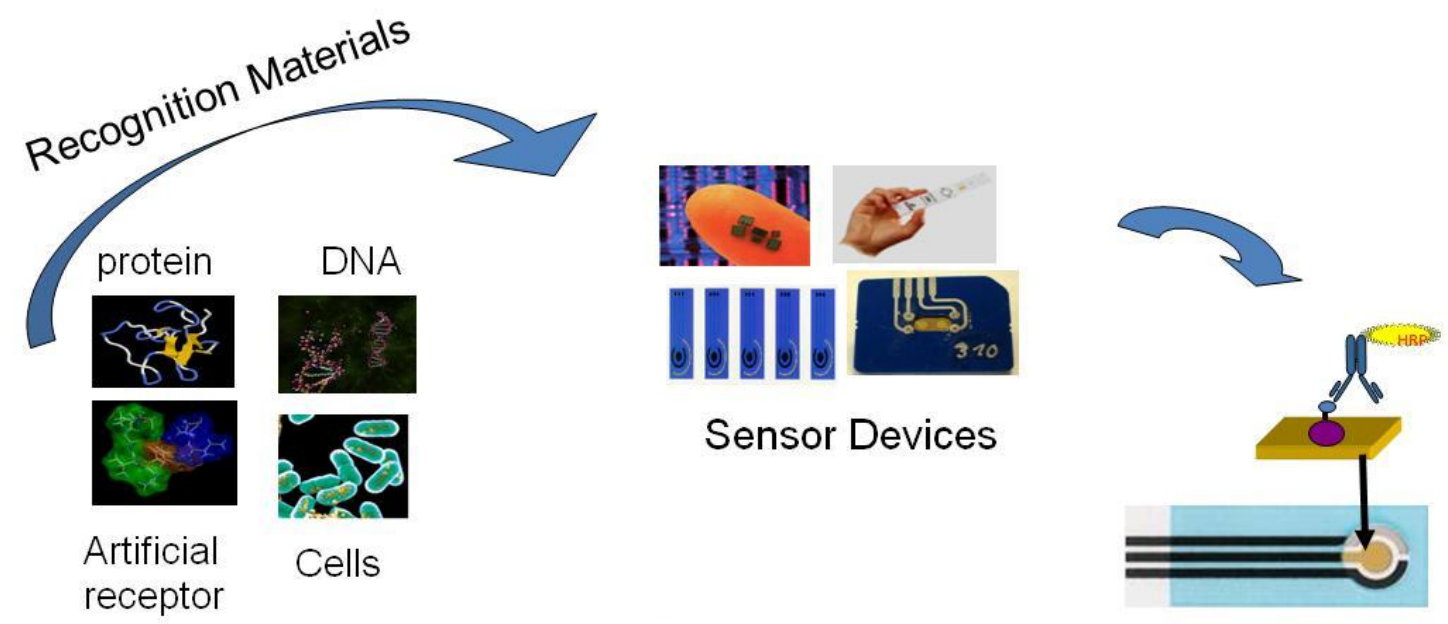

Assay development on the surface of the sensor device

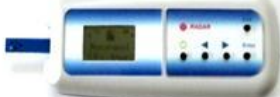

Instrument with

the sensor attached

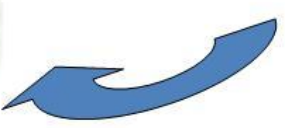


Figure 3: Different types of micro and nanoelectrodes arrays. A) Microdisk electrode, B) Microband electrode, C) Interdigiated microelectrode array and D) Three dimensional microelectrode array (Huang et al., 2009).
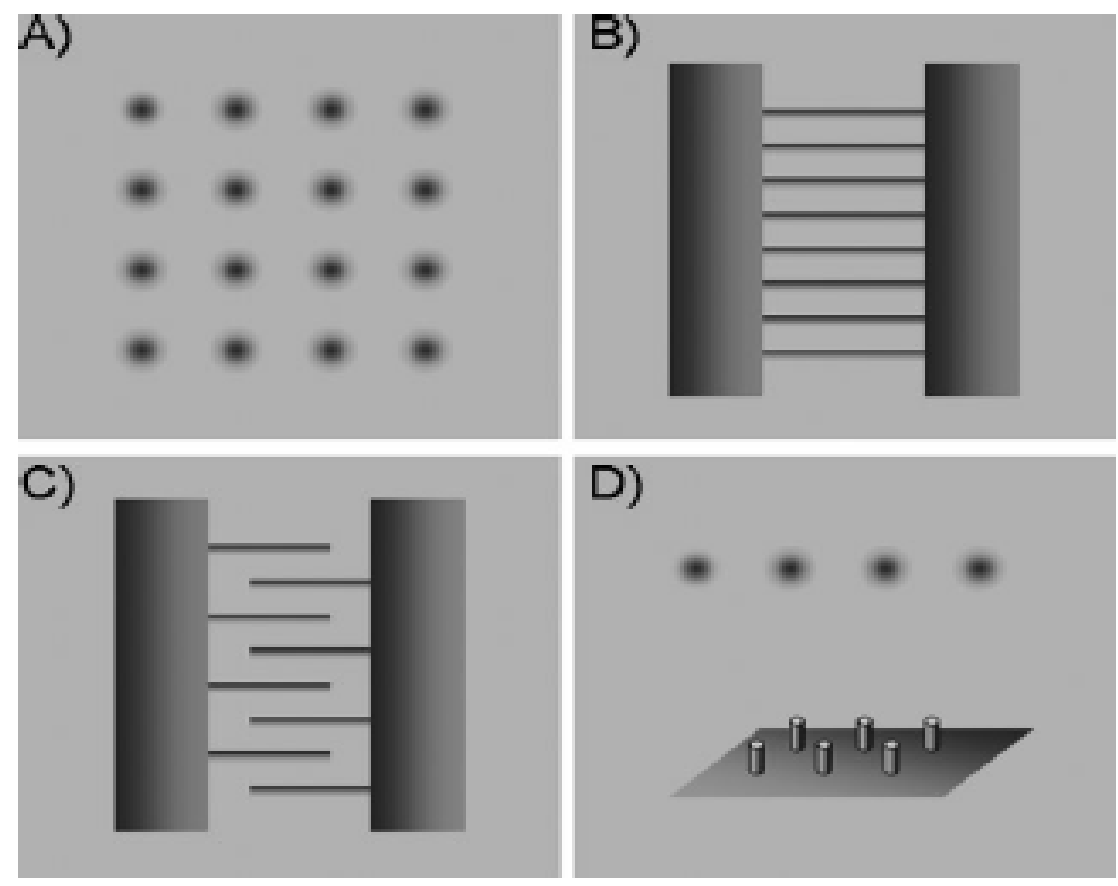
Figure 4: A three-electrode chips with a working electrode area (35 electrodes in the array), a counter electrode and a reference electrode area (Parker et al., 2009).

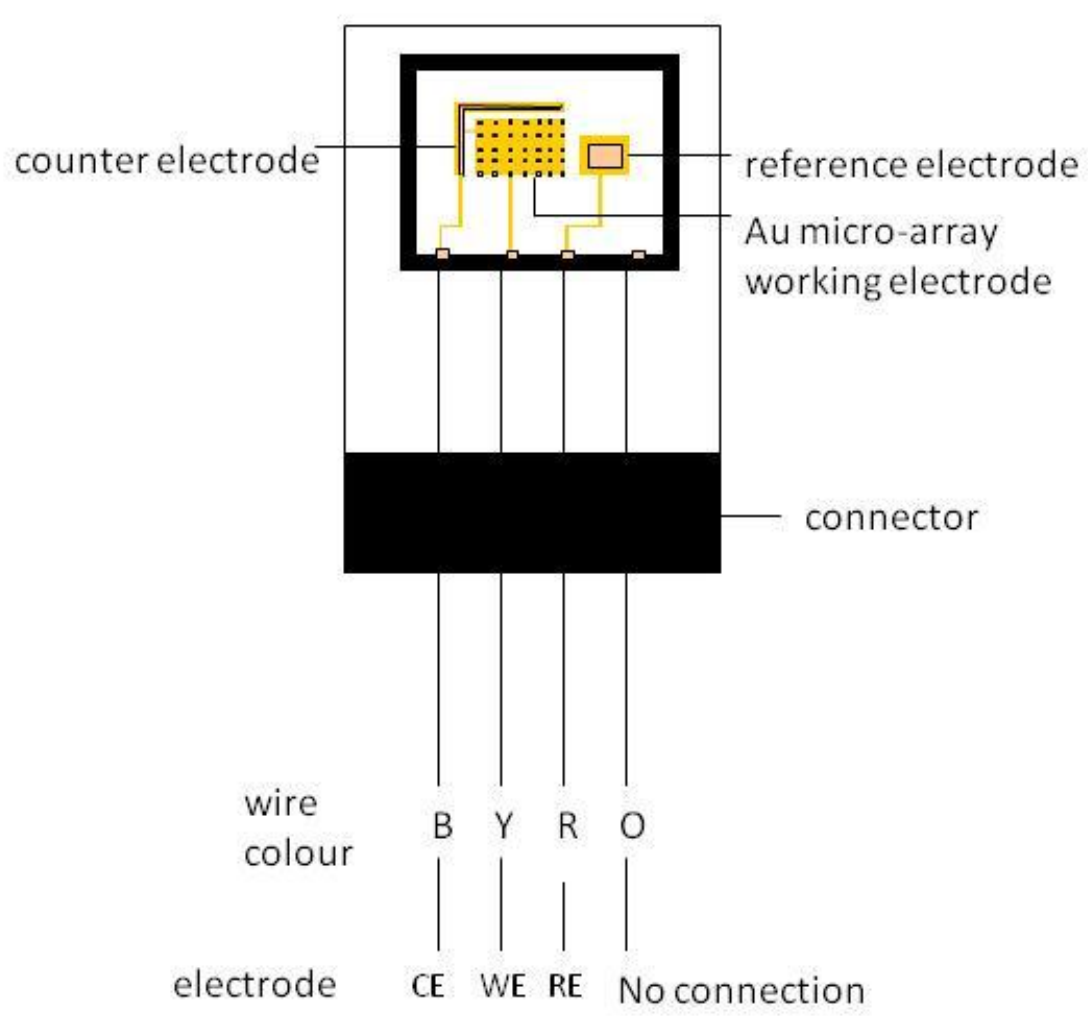

35 array

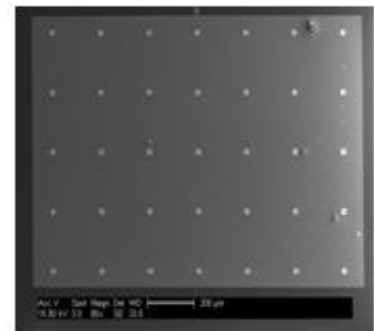

